\title{
ANÁLISE, MODELAGEM E IMPRESSÃO 3D DE UM FRAME PARA VANTS DO TIPO QUADRÍCOPTEROS PARA VOOS EM AMBIENTE INDOOR
}

\author{
Rafael da Rocha Gomes ${ }^{1}$ \\ Helosman Valente de Figueiredo ${ }^{2}$ \\ Alessandro Corrêa Mendes ${ }^{3}$ \\ Marcio Tadeu de Assis Honorato Muella ${ }^{4}$
}

Resumo: O foco do projeto de pesquisa foi analisar, modelar e construir utilizando uma impressora 3D, um frame de um Veículo Aéreo Não Tripulado (VANT) para voos em ambiente indoor. Esta aeronave será usada para experimentos laboratoriais, que exijam características especiais para ambientes indoor e de pesquisa, tais como, ser compacto, leve e uma estrutura que minimize os riscos aos operadores, pois dividirá espaço com pessoas. A motivação desta pesquisa se deu pelo fato dos frames disponíveis no mercado serem voltados para voos outdoor, como por exemplo, os utilizados para monitoramento. Com o intuito de proporcionar uma solução de aeronave para espaço laboratorial indoor, a proposta deste trabalho foi de modelar e imprimir em $3 D$ um protótipo de frame que atenda todos os requisitos necessários para este tipo de voo.

Palavras-chave: Vant impresso 3D; Vant indoor; Quadricoptero.

\footnotetext{
1 Engenharia/Universidade do Vale do Paraíba, Brasil. E-mail: rochagomes39@gmail.com.

2 Engenharia/Universidade do Vale do Paraíba, Brasil. E-mail: helosman@gmail.com.

${ }^{3}$ Engenharia/Universidade do Vale do Paraíba, Brasil. E-mail: alcomen@univap.br.

${ }^{4}$ Engenharia/Universidade do Vale do Paraíba, Brasil. E-mail: mmuella@univap.br.
} 